\title{
Blood-delivering drones saving lives in Africa and maybe soon in Canada
}

\author{
n Cite as: CMAJ 2018 January 22;190:E88-9. doi: 10.1503/cmaj.109-5541
}

Posted on cmajnews.com on Jan. 3, 2018.

W


was told her infant daughter and would need a blood transfusion, her heart sank. Her first thought was that the struggling Ariana wouldn't make it. "I had no hope," she said. had malaria-induced anemia

using drones to deliver blood to remote villages in East Africa. The project has been a roaring success, and the entrepreneurs behind it are in talks with health officials around the globe. Doctors in Northern Canada are among those eyeing the technology.

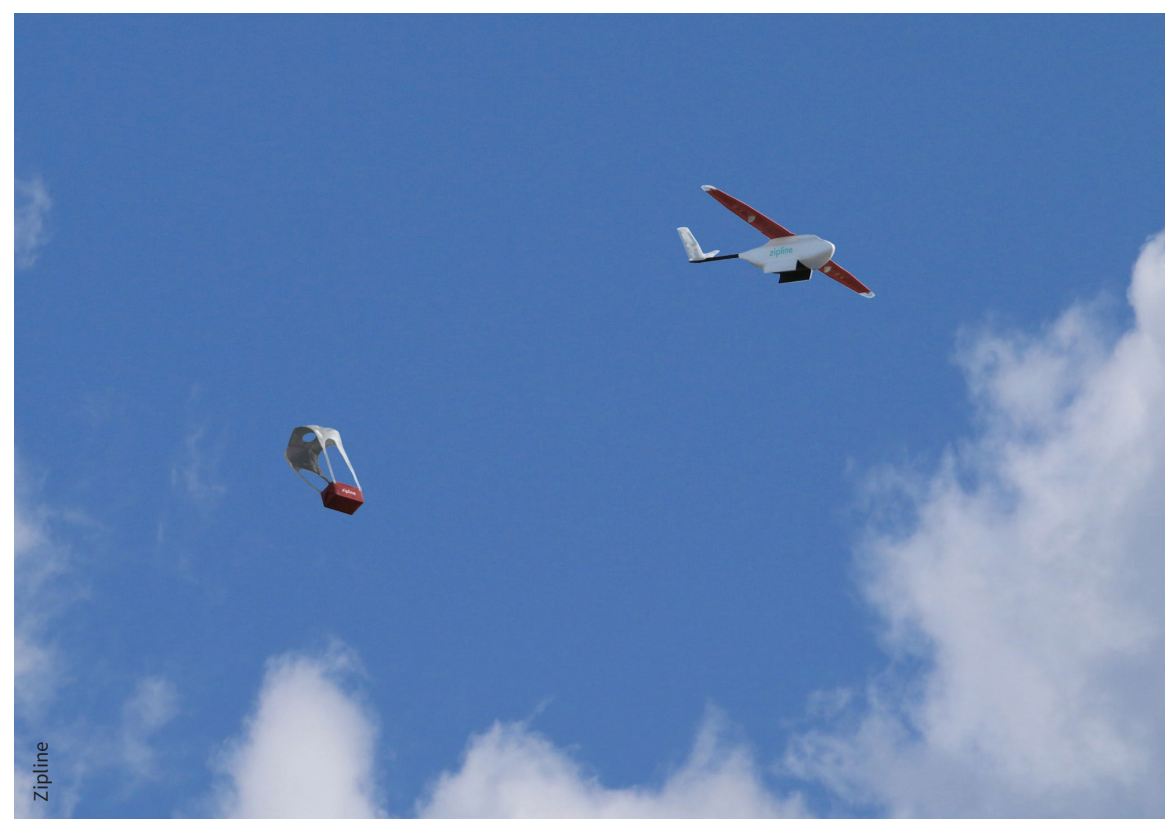

Blood descends via parachute in Rwanda after being delivered to a hospital by drone.

When she'd given birth a year earlier, the blood Niyomusenga needed for a transfusion took many hours to arrive to her region in Western Rwanda. This time, however, just minutes after arriving at the hospital, she was told to undress her baby for the transfusion - the blood was almost there. It was being delivered by a drone. Today when Niyomusenga sees a drone above, she smiles, "knowing it's on the way to save others."

A California-based startup called Zipline is behind the technology. It is
Since 2011, Zipline has been working with the government of Rwanda to deliver blood supplies to about 21 regional hospitals - launching more than 50 drones daily for on-demand deliveries. The company is planning to soon deliver vaccines and medicines to hundreds of clinics in Rwanda, and also in Tanzania. According to a press release from the government of Tanzania, the drones are expected to make 2000 deliveries a day.

"The lack of paved road infrastructure in these countries makes running a road- based delivery network really difficult," said Keenan Wyrobek, cofounder and head of product and engineering at Zipline. "There's nothing worse than a doctor who can't help a patient simply because of a lack of supplies."

Before Zipline, blood would often expire on the shelf in Rwanda. That is no longer a problem. Doctors can request blood on demand, by calling or placing orders online, and it generally arrives within 30 minutes. The drones gauge wind speed and direction when releasing a package, with its own parachute, so that it falls in a dedicated area. Round trips are 150 kilometres or less, and each drone makes a single drop before returning to the distribution centre. One of the biggest challenges has been navigating deliveries through mountain passes or during storms.

"Near the equator, weather is very localized and very unpredictable," said Wyrobek.

The Rwanda Ministry of Health is gathering data on how the drones are affecting health indicators. The blood sent by drone is often used for post-birth blood loss and to treat malaria-induced anemia. "Basically, it's very doable to save a woman's life if they have blood, and it's very hard to save that woman's life if they don't," said Wyrobek. "In terms of value to society, there's not only the loss of a life, but also a child growing up without a mother, so I think we've made a big impact on communities."

Another major benefit is that doctors can treat patients in regional hospitals with blood plasma and platelets to promote clotting. Previously, patients who needed these products would be sent to 
the capital, Kigali, which could be hours away. Local hospitals didn't have the high-tech freezers required for the blood products. Now drones send the plasma and platelets when needed, making storage unnecessary.

Zipline is in talks with interested parties in other African countries, as well as in South America and South-East Asia. After presenting at this year's TEDMED conference, several Canadian doctors approached Wyrobek about bringing the drones to the north. Wyrobek imagines a future in which drones deliver medications not just to hospitals or clinics, but also to individuals with chronic conditions who are isolated in fly-in communities.

"We really want to go where the problems are the biggest, and Northern
Canada is definitely on that list," said Wyrobek.

Wendy Glauser, Toronto, Ont.

Disclaimer: The Canadian Medical Association (CMA) is a global partner of TEDMED, but as with all CMAJ articles, the CMA and its subsidiaries, including Joule, owner of CMAJ, were not involved in the editorial decision-making process for this article. 